\title{
THEORETICAL BASIS OF NEW METHODOLOGY OF MATHEMATICAL-STATISTICAL DECISION MAKING WITH THE HELP OF BIOMARKERS FROM MASS SPECTRA
}

\author{
Jiři Knižzek \\ Charles University in Prague, Faculty of Medicine in Hradec Králové, Czech Republic: Department of Medical Biophysics
}

Key words: Biomarker; Decision Making; Mass Spectra; Proteom

There are at disposal $N_{S}$ mass spectra for the group of $N_{S}$ provably sick patients, $N_{H}$ mass spectra for the group of $N_{H}$ provably healthy patients and finally $N_{E}$ mass spectra for patient whose state of health is being examined. With this quite general data a doctor in clinic should make decision about null hypothesis

$$
H_{0} \text { : patient is healthy }
$$

(against alternative that patient is not healthy) as correctly as possible. In addition this doctor should make decision about miscellaneous null hypotheses

$$
\begin{gathered}
H_{0} \text { : patient is healthy in } \\
\left\langle x_{j_{1}} ; x_{j_{2}}\right\rangle \cup\left\langle x_{j_{3}} ; x_{j_{4}}\right\rangle \cup \ldots \cup\left\langle x_{j_{2 m-1}} ; x_{j_{2 m}}\right\rangle
\end{gathered}
$$

where $\left\langle x_{j_{1}} ; x_{j_{2}}\right\rangle \cup\left\langle x_{j_{3}} ; x_{j_{4}}\right\rangle \cup \ldots \cup\left\langle x_{j_{2 m-1}} ; x_{j_{2 m}}\right\rangle$ is unified set of $m$ intervals on the whole spectral range respecting single biomarkers, or respecting (certain biologically autonomous) groups of biomarkers. The proposed Theoretical basis of new methodology of mathematical-statistical decision making with the help of biomarkers from mass spectra enables to solve these thorny problems. The new methodology, as opposed to the methods $(1,2)$ used so far, solves the problems universally.
Nowadays this proposal is discussed in detail through e-mail with firms Geneva Bioinformatics S.A. (Prof. Ron D. Appel, Ph.D. and Dr. Frdrique Lisacek, Ph.D.) and Bruker Daltonik GmbH in Bremen (Dr. Wolfgang Pusch, Ph.D.).

\section{References}

1. Tibshirani R, Hastie T, Narasimhan B, Soltys S, Shi G, Koong A, Le QT: Sample classification from protein mass spectrometry by "peak probability contrasts", Bioinformatics - Bioinformatics Advance Access, Oxford University Press 2004; $1-34$.

2. Wu B, Abbott T, Fishman D, McMurray W, Mor G, Stone K, Ward D, Williams K, Zhao H: Comparison of statistical methods for classification of ovarian cancer using mass spectrometry data, Bioinformatics 2003;19:13:1636-43.

Submitted October 2004.

Accepted December 2004.

Dipl. Ing. Jiři Knížek, PhD.,

Charles University in Prague, Faculty of Medicine in Hradec Králové, Department of Medical Biophysics, 50038 Hradec Králové, Czech Republic. e-mail:knizekj@lfhk.cuni.cz 